\section{Daylight Auroras}

I HAVE frequently seen the appearances described by $\mathrm{Mr}$. Winstanley in your issue of August 3 , and $\Upsilon$ think I must have seen the one he mentions. I have on two occasions watched similar phenomena caused by the moon. These phenomena require the cloud or clouds, from which they are formed, to be of about the same azimuth as that of the sun (or moon), and vary witls the form and motion of the cloud, being, I think, simply a deflection of the sun's rays from the more salient points of the cloud. The streamers I saw on June 27 (sce Nature of July 9) were of an entirely different nature, rising near the south horizon somewhat to the east of the meridian, and flashing towards the moon, which had recently passed the meridian, while the sun was near setting in the N.W.

I have had nearly thirty years' experience in observing, and have no doubt that what I described were true streamers of an aurora australis.

Radcliffe Observatory, Oxford, Aug. I 7

\section{The Late Thunderstorm}

THE thunderstorm which has just broken up the spell of hot weather for the past week presented some peculiar features as seen from this place. Commanding rather a wide horizon, I noticed about 8.30 last evening two distinct centres of disturbance, one S.W., the other N.E. It is impossible to estimate the distance by sound, as the thunder was inaudible. The electric spark, however, was visible enough, and I noticed that with one exception it went invariably from $\mathrm{S}$. to $\mathrm{W}$. in the one case, and from N. to E. in the other, and always horizontally from cloud to clond. When I came out again at ro.I5 I found the two centres had moved, so that one was slightly S. of E., and the other N. of W., but still directly opposite each other. It seems, too, that they had gone in the direction in which the electric spark had passed.

This seemed to me interesting, and I thought your readers miglit find it so too.

Upron-on-Severn, Ang. 14

W. M. RORERTS

\section{Sir William Thomson and the Origin of Life}

I AM sure that Sir William Thomson will feel gratified rather than annoyed to be informed that he has been anticipated in his remarkable hypothesis regarding the origin of life on ourglobe.

In a very curious book called "A Visit to my Discontented Cousin." published some months ago, there is a portion of one chapter headed "The Aerolite." The "Discontented Cousin" having seen and heard a discussion on a meteoric stone, went home and "dreamt a dream," in which he saw the surface of the mass undergo various changes, and organic dots appear, one of which began to wriggle, rose to its microscopic legs, and confronted "the dreamer with a bold and self-confident mien."

This microscopic man, after having enjoyed "a glass of something stiff and a pipe," told the story of his own planet, beginning with the not very complimentary remark, "We know all about you, odd boy, and the British Association; and we don't think much about you, either."

For the story itself I must refer to pp. I86-192 of the took.

Torquay, Aug. 8

G. E. D.

\section{Meteorology at Natal}

IN your issue of November ro last I was glad to see that you were alive to even humble efforts to assist science in so distant a place as Natal by your remark on the new Meteorological Observatory for the Lurban Station.

As it may be interesting also to know what has been done, I append a list of the instruments ordered by the Natal Government. They are to supplement a few already on board. Unfortunately for the furtherance of this object, the state of affairs at present will not admit of any large expenditure of public money in this clirection, but I have been enabled to get the sum of $10 \%$. in 1870 and $25 \%$. in 1871 for the purchase of instruments. The Government, at the same time, pay the observer $12 \%$. per annum for the trouble of registering the results regularly.

At present the military authorities have an observatory at Fort Napier, in Pietermaritzburg, at a height of 2,200 feet above and forty-five miles from the sea. A station on the coast was required to complete the observations, and the Government liberally came forward with the means. Hitherto a system of registration has been followed in which the instruments were suspended in wooden boxes agninst the sides of dwelling-houses. Though such a system, perhaps, is advisable as giving the temperature ordinarily felt by residents, it nevertheless is more or less uncertain for the purposes of comparison, from the fact of some of the dwellings being built of wood and others of stone, and again some roofed with slates and others with galvanised iron.

The present system is that pursued by the military authorities. The thermometers are placed under a Glaisher's stand in the open air. Whether the military authorities are right or wrong matters little so long as one universal system is pursued, so that exact comparison can be made between each station. The results will always be sent to the Meteorological Society of England, and published in the Colonial Blue Book for each year.

Pietermaritzburg, Natal, May 16

VINCENT ERSKINE

P.S. - I expect the Observatory to te in thoroughly good order from the Ist of January, 1872.

\section{On the Colours of the Sea}

THE following is submitted on the above subject, referred to in NATURE of July 13 , as showing that the colour of the sea is not altogether dependent on the purity and depth of the water. At Zante, and southward as far as I have seen, it is of a deep blue at midday, but in the evening it is that described by Homer as "wine-like." I have observed this particularly when passing Navarino and Cape Mataplan. At night, looking down upon it from the steamer, it is quite black, lighted up, where the waves are broken, with white phosphorescent light.

I had once the gratification of seeing the whole of the solar spectrum spread out upon the sea, at Zante, on December 26 , 1861. The weather was very unsettled at the time. During an interval, when the rain had ceased, a little before Io A.M., the light of the sun descended from behind a cloud, and was reflected up to the height on which I was standing. Purple was the most remote coloin ; red the nearest; the space between was occupied by the other colours, of which green, yellow, and blue were the most marked.

JGHN J. LAKE

\section{Origin of Cyclones}

IN NATURE of $23 \mathrm{rd}$ of June, $187 \mathrm{I}$, there is an account of a paper, by Mr. Melcrum, on the origin of storms in the Bay of Bengal, showing reason to believe that the cyclones of the Bay of Bengal and the Southern Indian Ocean originate in the meeting of the trade-winds of the northern and southern hemispheres at some distance north or south of the equator. I do not know of any equally complete evidence on the subject for the cyclones of other parts of the world, but there is very strong reason for thinking that they always so originate. The line along which the two trade-winds meet each other approximately coincides with the equator: when it actually or nearly coincides with the equator, no cyclones are formed, because the rotation of a cyclone depends on that of the earth, and the earth at the equator has no rotation round an axis drawn vertical to the horizon. Over the greater part of the Pacific, cyclones do not appear to be formed : the reason of this probably is, that in consequence of the temperature of the sea changing but little with the seasons, the two trade. winds over the Pacific meet each other nearly on the equator all the year round; though I do not know how far this is confirmed by observations on the winds of that ocean. But we know that in the Indian Ocean the trade-winds cross the equator and are deflected into monsoons, so that in the summer of the northern hemisphere they meet to the north of the equator, and in the summer of the southern hemisphere they meet to the south. (This statement as to seasons will have to be qualified presently.)

We may consequently expect to find that the farther the sun is from the equator, the farther from the equator will be the meeting of the trade-winds, and consequently also the cyclones. This is the fact. In Dove's "Law of Storms," translated by Mr. Scott, at page 193, there is a cliart of the tracks of the cyclones of the Chinese Sea, which shows that they occur in all months from June to November, and that the later in the season the nearer to the equator is usually their track. In the Chinese Sea, where they are called typhoons, they are most numerous in the summer months; in the Bay of Bengal they are most numerous after the equinoxes. This will appear 